Canadian

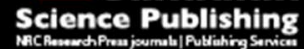

Canadian Journal of Chemistry Revue canadienne de chimie

\title{
Pressure Selected Reactivity between 2-Butyne and Water Induced by Two-Photon Excitation
}

\begin{tabular}{|r|l|}
\hline Journal: & Canadian Journal of Chemistry \\
\hline Manuscript ID & cjc-2017-0155.R1 \\
\hline Manuscript Type: & Article \\
\hline Date Submitted by the Author: & 21 -Jun-2017 \\
\hline $\begin{aligned} \text { Complete List of Authors: } \\
\text { Is the invited manuscript for } \\
\text { consideration in a Special } \\
\text { Issue?: }\end{aligned}$ & $\begin{array}{l}\text { Guan, Jiwen; University of Western Ontario, Department of Physics \& } \\
\text { Daljeet, Roshan; University of Western Ontario, Department of Chemistry } \\
\text { Song, Yang; University of Western Ontario }\end{array}$ \\
\hline Keyword: & $\begin{array}{l}\text { Diamond anvil cell, High pressure, FTIR spectroscopy, 2-Butyne, } \\
\text { Photochemistry }\end{array}$ \\
\hline
\end{tabular}




\title{
Pressure Selected Reactivity between 2-Butyne and Water Induced by Two-Photon Excitation
}

\author{
Jiwen Guan ${ }^{\dagger}$, Roshan Daljeet $^{\ddagger}$ and Yang Song* ${ }^{*}, \dot{\dagger}$ \\ ${ }^{\dagger}$ Department of Physics and Astronomy, University of Western Ontario, London, Ontario \\ N6A 3K7, Canada \\ Department of Chemistry, University of Western Ontario, London, Ontario N6A 5B7, \\ Canada
}

*Corresponding author. Email: yang.song@uwo.ca.

This article is part of a special issue dedicated to Prof. T. K. Sham of Western Chemistry. 


\begin{abstract}
:
High-pressure photochemistry between 2-butyne $\left(\mathrm{H}_{3} \mathrm{CC} \equiv \mathrm{CCH}_{3}\right)$ and trace amount of $\mathrm{H}_{2} \mathrm{O}$ was investigated at room temperature using multiline UV radiation at $\lambda \approx 350 \mathrm{~nm}$ and monitored by FTIR spectroscopy. Instead of the expected polymerization of 2-butyne, the IR spectral analysis suggests the formation of the cis-, trans-2-butene as well as 2-butanone as the primary products. The possible reaction mechanisms and production pathways of these products were examined, where the dissociation of water molecule as the other reactant are believed as the essential steps of the photochemical reaction. We further found that initial loading pressure of the mixture can not only substantially influence the reaction kinetics but also regulate the accessibilities to some reaction channels, which was evidenced by quantitative analysis of the characteristic IR bands of 2-butene and 2-butanone. The relative abundance of two products is found to be highly dependent on pressure and radiation time. This study provides attractive physical routes in the absence of solvents, catalysts, and radical initiators, to synthesis the relevant products with a great selectivity and feasibility.
\end{abstract}

Keywords: Diamond anvil cell, High pressure, FTIR spectroscopy, 2-Butyne, two-photon absorption 


\section{INTRODUCTION}

Application of external pressure on molecular systems can effectively shorten the intermolecular and intramolecular distances, thus subsequently causing reversible or irreversible transformations in the molecular structures and associated electronic, optical, or mechanical properties. $^{1,2}$ Therefore, pressure becomes one of the most effective tools to produce new materials even starting from simple molecular solids, especially those with unsaturated bonds or conjugate ring structures. ${ }^{2,3}$ For example, pressure induced transformations have been reported for acetylene, ${ }^{4}$ cyanogen, ${ }^{5}$ butadiene, ${ }^{6}$ benzene $^{7}$ and others. ${ }^{2}$ These transformations, however, require pressures ranging from several to dozens of gigapascals (GPa). As a result, the application of these reactions to produce useful materials is strongly limited by the high pressures required and thus is difficult for large scale production. Recently, the electronic excitation by laser photons has been demonstrated a very efficient way in reducing the threshold pressure for polymerization and other reactions. ${ }^{8}$ Moreover, an enhanced selectivity and/or the access to new reaction paths might be also achieved. ${ }^{9,10}$ Thus, the combination of high pressure and electronic excitation provides attractive alternative routes to synthesize novel materials.

Selective electronic excitation of a reactant molecule can initiate a reaction not just by bringing the molecule to the necessary activation energy level, but also by changing the molecular symmetries and electronic configurations, opening an otherwise inaccessible reaction paths. The excited molecule can have a reduced bond order that determines bond strengths and molecular reactivity, a lowered rotational or torsional barriers, an increase in the polarity, and even spontaneous dissociation and ionization characters. ${ }^{11}$ The electronically excited molecules can be particularly aggressive from a chemical point of view and, depending on their lifetime and free mean path, can trigger and propagate a reaction to a different extent under different physical 
conditions. Therefore, high pressure may efficiently promote photoreactions because the increasing density of the materials results in reduced intermolecular distances that favor the interaction between electronic excited state and ground state molecules. The efficiency of these processes has been studied in pure condensed unsaturated hydrocarbon systems using near-UV excitations from continuous or pulsed wave laser sources., ${ }^{9,10,12-15}$

Among unsaturated hydrocarbons with triple bonds, for example, polymerization of acetylene as the simplest model system has been studied by applying high pressure and/or laser-assisted high-pressure methods. ${ }^{4,16,17}$ High pressure reactivity of 2-butyne as a substituted acetylene, in contrast, is much less understood. Upon compression, Baonza et al. reported two phase transitions at 0.2 and $0.9 \mathrm{GPa}$ deduced from the pressure evolution of Raman spectra of 2butyne. $^{18}$ Above $2.6 \mathrm{GPa}$, the rotation hindrance of the methyl groups along the molecular axis was indicated and no polymerization of 2-butyne was observed up to $4 \mathrm{GPa}$, indicating that much higher pressure is required for polymeric transformations. Polyacetylene and poly(2-butyne) as conductive polymers have a very attractive electrical conductivity induced by the conjugated bonds. For instance, combination of doping and photoexcitation of polyacetylene led to substantially enhanced electrical conductivity comparable to that of amorphous carbon. ${ }^{19}$ Therefore, understanding the high-pressure reactivity of 2-butyne is of great interest in producing useful materials.

Photochemical reactivities of alkynes have been investigated in mono- or di-substituted acetylenes in which the substituents are alkyl, aryl or alkoxycarbonyl. ${ }^{20}$ Many simple alkynes are reported to undergo efficient hemolytic bond cleavage on (vacuum) ultraviolet irradiation in the vapor phase. For instance, the cleavage of 2-butyne at shorter wavelengths gave rise to a diyne (eq. 1)..$^{20}$ 


$$
\mathrm{CH}_{3} \mathrm{C} \equiv \mathrm{CCH}_{3} \stackrel{h v}{\rightarrow} \mathrm{CH}_{3} \mathrm{C} \equiv \mathrm{CH}_{2} \mathrm{CH}_{2} \mathrm{C} \equiv \mathrm{CCH}_{3}+\mathrm{CH}_{3} \mathrm{CH}=\mathrm{CHCH}_{3}
$$

Unlike the wealth of photochemistry reported for alkenes, alkynes have a greater tendency to undergo photopolymerization than any other reactions upon irradiation particularly in solution phase. Thus, applying pressure on liquid 2-butyne could even further favor the photopolymerization of the sample. Given the very high projected pressure required for the polymerization of 2-butyne, in particular, laser activation might lower the pressure threshold for polymerization and other reactions. In this work, we apply near-UV radiation on condensed 2butyne at high pressures and monitor photoreactions by FTIR spectroscopy. We found that 2butyne is highly reactive when mixed with even a small amount of $\mathrm{H}_{2} \mathrm{O}$ to produce distinctive products selectively at different pressures, although the polymerization is still not favored under that combined pressure-photon conditions. The observed reactions and products demonstrate the feasibility and efficiency of a pure physical route to synthesis the relevant materials with great selectivity and controllability.

\section{EXPERIMENTAL SECTION}

2-butyne (purity $\geq 98 \%$ ) was purchased from Alfa Aesar and used as obtained. A symmetric diamond anvil cell (DAC) equipped with a pair of type II diamonds with a culet size of $600 \mu \mathrm{m}$ was used to generate the high static pressure. Briefly, a ruby ball was firstly loaded into a hole with a diameter of $250 \mu \mathrm{m}$ drilled on a stainless steel gasket that was pre-indented to a thickness of 30-50 $\mu \mathrm{m}$. Then 2-butyne was cryogenically loaded into the DAC that was pre-cooled with dry ice due to the high volatility of 2-butyne at room temperature (i.e., boiling point: $27{ }^{\circ} \mathrm{C}$ ). During this loading process, a small amount of water condensed from the surrounding air were loaded as well. The pressure was determined using the well-established ruby fluorescence method. Excellent system hydrostaticity was observed due to liquid state of the sample and 
relatively low-pressure range (i.e., $<1 \mathrm{GPa}$ ). The loaded samples were compressed to different initial pressures of $0.04,0.14,0.27,0.52$, and $0.9 \mathrm{GPa}$ for different runs all at room temperature. The relative ratios of 2-butyne and $\mathrm{H}_{2} \mathrm{O}$ in the DAC for each loading were estimated from the IR spectra (see Fig. 1a). Specifically, the relative amount of 2-butyne and $\mathrm{H}_{2} \mathrm{O}$ are estimated by integrating the IR band $2 v_{3}$ of 2-butyne and $\mathrm{OH}$ stretching mode of $\mathrm{H}_{2} \mathrm{O}$, respectively. The relative intensities of $2 v_{3}$ band of 2-butyne for each loading pressure are normalized to $100 \%$ while the maximum water content loaded at $0.52 \mathrm{GPa}$ is arbitrarily set with 1:1 ratio with 2butyne as the reference level to allow the estimate of relative amount of water loaded at other pressures. No reactivity for 2-butyne and $\mathrm{H}_{2} \mathrm{O}$ mixture under high pressure at ambient temperature was found, which was evidenced by the invariant IR spectra collected from a fresh loading sample to up to 240 hours aged under $0.5 \mathrm{GPa}$.

For each loaded sample under high pressure, reactions were triggered by focusing the multiline UV emission with a peak wavelength of $\sim 350 \mathrm{~nm}$ from an argon ion laser onto the sample with a beam size of $\sim 60 \mu \mathrm{m}$ in diameter and a power $250 \mathrm{~mW}$. The reaction progress was monitored by IR spectroscopy with the IR absorption spectra collected at a 5-10 min interval. The reactions were determined completely when no further spectral changes were observed (see Results and Discussion). For IR absorption measurements, a customized IR micro-spectroscopy system that consists of a Fourier transform IR (FTIR) spectrometer from Bruker Optics (model Vertex 80v) equipped with a Globar mid-IR light source was used. The detailed instrumentations have been described elsewhere. ${ }^{21}$ The system was operated under a vacuum of $<5$ mbar, such that the absorption by $\mathrm{H}_{2} \mathrm{O}$ and $\mathrm{CO}_{2}$ was efficiently removed. The reference spectrum (i.e., the absorption of diamond anvils that was collected before samples were loaded) was divided as the background from each measurement. The spectral resolution used was $4 \mathrm{~cm}^{-1}$. 


\section{RESULTS AND DISCUSSION}

\section{A. Pressure-induced phase transitions of 2-butyne below 1.4 GPa}

As a starting point, we performed multiple loadings of 2-butyne samples with different initial pressures and collected the IR absorption spectra as reference (shown in Fig. 1a) prior to the irradiation with UV laser. IR absorption bands of 2-butyne and their assignments at the lowest initial pressure of $0.04 \mathrm{GPa}$ are listed in Table 1, which are consistent with the previous report using Raman spectroscopy. ${ }^{18}$ Careful analysis indicates that for all samples, trace amount of water was trapped in the sample chamber during the cryogenic loading as indicated by the broad OH IR absorption band around $3300 \mathrm{~cm}^{-1}$. Quantitative analysis of the IR intensity allows the estimate of water content as indicated in Fig 1a. Pressure-induced phase transitions of 2-butyne leading to the changes in intermolecular distances and orientations of molecules in different phases has been reported previously. ${ }^{18}$ Therefore, frequency shifts of characteristic IR modes of 2-butyne upon compression are plotted in Fig. $1 \mathrm{~b}$ to examine the possible pressure-induced phase transitions. Pressure dependence of IR modes at $1440\left(v_{14}\right), 2740\left(2 v_{3}\right), 2860\left(2 v_{14}\right), 2920\left(v_{1}\right)$ and $2960\left(v_{13}\right) \mathrm{cm}^{-1}$ clearly show two phase transition boundaries. The first boundary at around $0.25 \mathrm{GPa}$ suggests the phase transition from liquid to solid phase I, which is consistent with the transition observed at $0.2 \mathrm{GPa}$ in previous Raman study of pure 2-butyne upon compression. ${ }^{18}$ Moreover, the full-width-at-half-maximum (FWHM) of IR band $v_{14}$ becomes much larger at 0.27 , $0.30,0.52 \mathrm{GPa}$ (i.e., $\sim 107 \mathrm{~cm}^{-1}$ ) than those in liquid phase (i.e., $\sim 50 \mathrm{~cm}^{-1}$ ). Concurrently, the intensities of IR modes $2 v_{14}, v_{1}$ and $v_{13}$ are significantly reduced. These observations indicate the molecular disorder in phase I. Indeed, a low-temperature neutron powder diffraction study on 2butyne suggested that this phase likely adopts a rhombohedral structure with three molecules per unit cell with highly disordered nature. ${ }^{22}$ The IR frequency shifts vs. pressure and appearance of 
new mode at $2740 \mathrm{~cm}^{-1}$ indicate another phase transition from phase I to phase II at $0.9 \mathrm{GPa}$, which is also consistent with the previous Raman study. ${ }^{18}$ The low-temperature neutron powder diffraction study indicated that phase II has a monoclinic structure(space group $\mathrm{C} 2 / \mathrm{m}$ ) with two molecules per unit cell (as shown in Fig. 1b). ${ }^{22}$

\section{B. Photochemical reactions of 2-butyne with $\mathrm{H}_{2} \mathrm{O}$}

Starting from these phases at pressures of 0.04 (liquid), 0.27 (liquid-phase I mixture), 0.52 (phase I), $0.90 \mathrm{GPa}$ (phase II), we carried out photochemical studies by irradiating the multiline $\mathrm{UV}$ at $\lambda \sim 350 \mathrm{~nm}$ with a power of $250 \mathrm{~mW}$. The reaction progress is monitored by visual observations under an optical microscope and by FTIR spectroscopy as a function of radiation time. We observed that the photon-induced reactions at $0.04 \mathrm{GPa}$ are same as the those at 0.27 GPa as evidence by almost identical IR evolution profiles. Here, we show the photochemical evolution at $0.27 \mathrm{GPa}$ as a representative (Fig 2a). Clearly, after $30 \mathrm{~min}$ irradiation, the new IR bands at 675 and $966 \mathrm{~cm}^{-1}$ appear and are intensified with further radiation. At 45 min, more IR bands, for instance, at $816,884,910,1065$ and $1303 \mathrm{~cm}^{-1}$ (Fig. 2a) as well as 1660, 1729 and $3020 \mathrm{~cm}^{-1}$ are observed (Fig. 3a). After $100 \mathrm{~min}$, these IR peaks become extremely intense but no more time-dependent changes of the IR profile were observed, indicating the completion of the photochemical reactions under the given conditions. As a result, a brownish solid as the product can be observed under the microscope as shown in the inset of Fig. 3a.

\section{B1. Partial hydrogenation of 2-butyne}

In order to identify the possible photochemical products, we examined the database of the characteristic IR absorption frequencies of several possible 2-butyne derivatives. The observed IR peaks at $969 \mathrm{~cm}^{-1}$ (=C-H bend) and $3020 \mathrm{~cm}^{-1}$ (=C-H stretch) both infers a possible formation of alkenes. By comparing the IR spectra at 30, 45 and 100 min with corresponding characteristic 
IR peaks of 2-butene in Table 2, the new peaks at 676, 969, 1661, 2862 and $3023 \mathrm{~cm}^{-1}$ exhibits an excellent agreement with the IR bands of solid cis 2-butene $\left(\mathrm{H}_{3} \mathrm{CCH}=\mathrm{CHCH}_{3}\right)$, which absorbs at $682,972,1661,2860$ and $3014 \mathrm{~cm}^{-1}$, respectively. ${ }^{23}$ From $30 \mathrm{~min}$ to $45 \mathrm{~min}$, the IR bands in the range of 2800-3000 $\mathrm{cm}^{-1}$ was significantly intensified (Fig. 3a), which also supports the progressive formation of cis 2-butene as the primary photochemical product (Table 1). In addition, we observed the slight shift of the peak at $966 \mathrm{~cm}^{-1}$ to $969 \mathrm{~cm}^{-1}$ at $45 \mathrm{~min}$ with a strong and relatively broad IR profile (Fig. 2a) as well as the appearance of new peaks at 1065 and 1303 $\mathrm{cm}^{-1}$ These features strongly suggest a photo-induced partial isomerisation of cis 2-butene to trans 2-butene as summarized in Table 2.

The formation of 2-butene infers a cleavage of the triple carbon-carbon bond of 2-butyne and subsequent reaction with $\mathrm{H}$ atoms. The source of $\mathrm{H}$ atoms therefore is of fundamental importance for the formation of 2-butene. As it will be discussed below, the energetics strongly disfavors the dissociation of hydrogen from methyl groups of 2-butyne, leaving the other reactant, $\mathrm{H}_{2} \mathrm{O}$ as the more probable source of hydrogen. The early studies showed that irradiating liquid water with VUV light favorably promotes the dissociation processes: ${ }^{24-26}$

$$
\mathrm{H}_{2} \mathrm{O}_{(l)}+h v \rightarrow \mathrm{H}_{(a q)}+\mathrm{OH}_{(a q)}
$$

Furthermore, the photon energies that can be effectively absorbed by liquid water were reported to be in the range of 6-6.5 eV..$^{27,28}$ Therefore, the energy required for reaction (2) can be achieved by two-photon absorption of $350 \mathrm{~nm}$ near-UV radiation (i.e., $7 \mathrm{eV}$ ) under the current experiment condition. By using the transient absorption spectroscopy, Cristopher et al. found that the average initial separation of $\mathrm{H}$ and $\mathrm{OH}$ fragments from the dissociation channel (2) at the lower excitation energy (e.g., $8.3 \mathrm{eV}$ ) is about $7 \AA$. The relatively large separation of the dissociation products suggests that $\mathrm{H}$ atoms are formed with enough kinetic energy to escape the solvent cage 
or several layers of solvent shells. ${ }^{26}$ Moreover, previous molecular dynamics calculations on the mobility of the $\mathrm{H}$ atoms and $\mathrm{OH}$ radicals also showed that $\mathrm{H}$ atoms could move long distances up to $60 \AA$ even through solid $\mathrm{H}_{2} \mathrm{O}$ and remain reactive. ${ }^{29}$ Under these conditions, it is therefore highly likely for liquid water to produce reactive radicals with the feasible photon energies. As shown in Fig. 4, the photodissociation of water via the two-photon process allows the production of a pair of radicals within the cage of water molecules. The $\mathrm{H}$ and $\mathrm{OH}$ radical pair can either escape the water cage and persist separately in solution or diffusively recombine to form the starting molecule. Alternatively, the radical pair could also remain the original water cage and recombine on a much faster timescale than for diffusive recombination. ${ }^{30}$ Therefore, water cages play a prominent role to sequestrate reactive $\mathrm{OH}$ radicals but release $\mathrm{H}$ atoms for subsequent reactions. Ultimately, the light $\mathrm{H}$ atom with enough kinetic energy survives the recombination process and thus favorably react with the carbon-carbon triple bond of 2-butyne to produce 2butene (Fig. 4).

\section{B2. Hydration of 2-butyne and tautomerism}

In addition to 2-butene, the IR profiles suggest the formation of other possible photochemical products. In Fig. 3a, for instance, the broad peak centered at $1729 \mathrm{~cm}^{-1}$ indicates the vibration of the carbonyl group. Together with IR bands at 752, 770 and $910 \mathrm{~cm}^{-1}$ observed in Fig. $2 \mathrm{~b}$, these characteristic peaks provide strong evidence for the formation of solid 2-butanone, which exhibits characteristic IR absorptions at 745, 768, 937 and $1716 \mathrm{~cm}^{-1}$ for instance (Table 2). ${ }^{31}$ The IR signatures for solid 2-butanone become more prominent at $0.52 \mathrm{GPa}$.

The formation of 2-butanone can be easily understood from the highly reactive nature of the $\mathrm{H}$ and $\mathrm{OH}$ radicals produced via the two-photon dissociation of water molecules by near-UV radiation at $350 \mathrm{~nm}$ at moderate pressures. It has been reported that these radicals are the 
essential initiators to induce chemical reactions in the mixtures such as red phosphorus- $\mathrm{H}_{2} \mathrm{O}$ system and in clathrate hydrates. ${ }^{11,32-34}$ Similarly, the highly reactive $\mathrm{H}$ and $\mathrm{OH}$ radicals can attack the triple bond of 2-butyne and undergo a photochemical anti-Markownikoff addition to produce the enol form $\left(\mathrm{H}_{3} \mathrm{CHC}=\mathrm{COHCH}_{3}\right)$ as the hydration product. In the IR spectrum, however, no enol form can be identified. Moreover, the hydration of alkyne has been alternatively achieved catalytically followed by tautomerization: ${ }^{35}$

$$
\mathrm{CH}_{3} \mathrm{C} \equiv \mathrm{CCH}_{3}+\mathrm{H}_{2} \mathrm{O} \rightarrow \mathrm{H}_{3} \mathrm{CHC}=\mathrm{COHCH}_{3} \stackrel{\text { tautomerization }}{\longleftrightarrow} \mathrm{C}_{2} \mathrm{H}_{5} \mathrm{COCH}_{3}
$$

Under ambient and catalytic conditions, reaction (3) suggests a tautomerism equilibrium between the enol and ketone forms. The fact that no enol form was observed in experiments suggests that the ketone is the energetically favorable form over the enol under the specific conditions where combined pressure-photon acts as an effective driving force for one-way tautomerization.

At higher pressure $0.9 \mathrm{GPa}$, interestingly, the IR spectra suggests that instead of 2-butene, only 2-butanone is produced (Figs. 2c, 3c and Table 2). The closure of the production channel for 2butene at this pressure could be primarily due to the fact that $\mathrm{H}_{2} \mathrm{O}$ and/or 2-butyne transformed to crystalline phases (Ice VI and phase II, respectively). At room temperature, specifically, the phase transition pressures for both liquid $\mathrm{H}_{2} \mathrm{O} \rightarrow$ Ice VI and phase I $\rightarrow$ phase II of 2-butyne were reported in pressure region of $0.9-1 \mathrm{GPa} .{ }^{18,36}$ The crystallization of water would significantly impact the formation of water cages which are essential to preserve the reactive $H$ atoms and thus the formation of 2-butene.

\section{Possibility of other photochemical reactions and polymerizations of 2-butyne}

We systematically investigated the pressure and water content influence on the photochemical reactions between 2-butyne and $\mathrm{H}_{2} \mathrm{O}$ in an extended pressure region and by varying the water content. However, no other reaction channels and especially the originally expected 
polymerization of 2-butyne was observed. To minimize the reactive contribution from $\mathrm{H}_{2} \mathrm{O}$, we loaded almost pure 2-butyne (e.g., at $0.14 \mathrm{GPa}$ where the extremely weak IR band of OH stretch suggests negligible water content as shown in Fig. 1a) for subsequent photochemical studies. However, the appearance of the most characteristic IR band at $969 \mathrm{~cm}^{-1}$ at $130 \mathrm{~min}$ radiation (the most intense IR peak of 2-butene and 2-butanone in Fig. 2) suggests that the reactions proceed still via the dissociation of $\mathrm{H}_{2} \mathrm{O}$ slowly instead of polymerization reactions of 2-butyne. Photochemical reactions of pure 2-butyne have been studied both experimentally and theoretically. ${ }^{37-39}$ Upon excitation by a $193 \mathrm{~nm} \mathrm{UV}(6.42 \mathrm{eV})$ laser, ${ }^{38}$ for instance, two dominant dissociation paths, were identified as follows. ${ }^{37,40,41}$

$$
\begin{aligned}
& \mathrm{H}_{3} \mathrm{CC} \equiv \mathrm{CCH}_{3} \rightarrow \mathrm{H}_{3} \mathrm{CC} \equiv \mathrm{CCH}_{2}+\mathrm{H} \quad 3.78 \mathrm{eV} \\
& \rightarrow \mathrm{H}_{3} \mathrm{CC} \equiv \mathrm{C}+\mathrm{CH}_{3} \quad 3.84 \mathrm{eV}
\end{aligned}
$$

However, the possible products from reactions of these fragements (e.g., $\mathrm{H}_{3} \mathrm{CC} \equiv \mathrm{CCH}_{2} \mathrm{CH}_{3}$, $\mathrm{H}_{3} \mathrm{CC} \equiv \mathrm{CH}$ ) can be ruled out by examining documented IR spectra of the products. Moreover, excitation energy at near-UV $350 \mathrm{~nm}(3.5 \mathrm{eV})$ in our experiment is insufficient to reach the reaction threshold.

\section{Selectivity and kinetics of the competitive reactions under pressure}

Finally, we examined the effects of loading pressures on the reaction kinetics quantitatively for more in-depth understanding of the reaction mechanisms. The yield of two primary products can be estimated by the integrated intensity of the characteristic IR bands, e.g., $675 \mathrm{~cm}^{-1}$ for 2-butene and $1729 \mathrm{~cm}^{-1}$ for 2-butanone. The integrated intensity of the characteristic peaks as a function of radiation time is plotted in Fig. 5. For 2-butene, the relative reaction yield suggests that low pressure (i.e., $<0.27 \mathrm{GPa}$ ) is favorable for its production whereas relatively high pressure (e.g., $0.52 \mathrm{GPa}$ ) significantly reduces the production. Moreover, the production channel for 2-butene is 
completely closed at $0.9 \mathrm{GPa}$ (see above discussion). For 2-butanone, in contrast, the relative reaction yield is less affected by different loading pressures. In particular, this production channel remains open even under high pressure of $0.9 \mathrm{GPa}$ (Fig. 5b).

In terms of reaction rate, evidently, higher loading pressures favor the faster kinetics for the production of both 2-butene and 2-butanone. Specifically, the reaction initiation time at $0.04 \mathrm{GPa}$ is significantly shortened from $\sim 100$ min to less than 20 min or almost instantaneous when the initial loading pressure is increased to $0.52 \mathrm{GPa}$. However, above $0.52 \mathrm{GPa}$ (e.g., $0.9 \mathrm{GPa}$ ), it reduces the reaction rate for 2 -butanone with initiation time close to $40 \mathrm{~min}$ (Fig. $5 \mathrm{~b}$ ). These observations show the similar pressure effect on photochemical reaction kinetics for ethylene glycol and styrene we reported previously, ${ }^{15,42}$ where pressure generally accelerates a photochemical reaction up to an optimal pressure beyond which the reaction is significantly slowed down and/or completely prohibited. In these studies, we established that the activation volume typically decreases with increasing pressure until reaching an optimal pressure giving a zero activation volume and thus a barrierless reaction. The reduced kinetics for the production of 2-butanone above $0.52 \mathrm{GPa}$ thus implies the activation volume reached the minimum at this pressure and increases significantly at $0.9 \mathrm{GPa}$. More importantly, higher pressure may substantially suppress the reaction channels that are dissociative in nature, such as the production of $\mathrm{H}$ and $\mathrm{OH}$ radicals from water. The reduced supplies of $\mathrm{H}$ and $\mathrm{OH}$ radicals as essential reactants for the production of 2-butanone may further contribute to the reduced reaction rate.

Overall, the pressure-dependent photochemical reactivity of 2-butyne $/ \mathrm{H}_{2} \mathrm{O}$ system provides important implications in the production of useful species with great tunability and controllability. In particular, the production of 2-butene can be a cost effective and efficient method to produce the precursor for the production of gasoline and butadiene. In addition, the 
unique synthesis of 2-butanone as an industrially versatile material that is currently produced on a large scale (i.e., 700 million kilograms annually ${ }^{43}$ ), may shed light on its production using an alternative approach. By carefully selecting the favorable pressure, temperature as well as the radiation energy, the reaction channels may be tuned and optimized to selectively generate the desired product. Furthermore, the method we use to synthesis these products are in the absence of solvents, catalysts, and radical initiators and thus greatly promote green chemistry.

\section{CONCLUSIONS}

In summary, the photon-induced reactivity of 2-butyne with trace amount of water was investigated in a diamond anvil cell at pressures up to $\sim 1 \mathrm{GPa}$ and ambient temperature. The near-UV radiation at $\lambda=350 \mathrm{~nm}$ was employed to initiate the photochemical reactions via twophoton absorption processes. In situ FTIR spectroscopy allows reaction progress to be probed in real time. Spectral analysis suggests the production of cis, trans-2-butene and 2-butanone from the photoreactions of the 2-butyne/water fluid at relatively lower loading pressures. At higher loading pressures of $0.9 \mathrm{GPa}$, only 2-butanone is selectively produced. The possible reaction mechanisms and pathways of these products are proposed, where the photodissociation of $\mathrm{H}_{2} \mathrm{O}$ are believed as the essential steps of the reactions. We further explored the pressure-dependence of the reaction kinetics for the production of 2-butene and 2-butanone. Both the reaction yield and rate are found to be highly pressure dependent, which could be understood in terms of activation volume as well as the production efficiency of radicals. The study demonstrates an attractive route to produce useful materials with great selectivity via an environmental friendly synthetic approach. 


\section{ACKNOWLEDGMENTS}

This work was supported by a Discovery Grant, a Research Tools and Instruments Grant from the Natural Science and Engineering Research Council of Canada, a Leaders Opportunity Fund from the Canadian Foundation for Innovation, an Early Researcher Award from the Ontario Ministry of Research and Innovation, and a Petro-Canada Young Innovator Award.

\section{REFERENCES}

(1) Schettino, V.; Bini, R. Phys. Chem. Chem. Phys. 2003, 5, 1951-1965.

(2) Schettino, V.; Bini, R.; Ceppatelli, M.; Ciabini, L.; Citroni, M. Adv. Chem. Phys., 2005, 131, $105-$ 242.

(3) Hemley, R. J. Annu. Rev. Phys. Chem. 2000, 51, 763.

(4) Aoki, K.; Usuba, S.; Yoshida, M.; Kakudate, Y.; Tanaka, K.; Fujiwara, S. J. Chem. Phys. 1988, $89,529-534$.

(5) Yoo, C. S.; Nicol, M. J. Phys. Chem. 1986, 90, 6726-6731.

(6) Citroni, M.; Ceppatelli, M.; Bini, R.; Schettino, V. J. Chem. Phys. 2003, 118, 1815-1820.

(7) Citroni, M.; Bini, R.; Foggi, P.; Schettino, V. Proc. Natl. Acad. Sci. 2008, 105, 7658-7663.

(8) Bini, R. Acc. Chem. Res. 2004, 37, 95-101.

(9) Citroni, M.; Ceppatelli, M.; Bini, R.; Schettino, V. Science 2002, 295, 2058-2060.

(10) Ciabini, L.; Santoro, M.; Bini, R.; Schettino, V. Phys. Rev. Lett. 2002, 88.

(11) Ceppatelli, M.; Bini, R.; Schettino, V. Proc. Natl. Acad. Sci. 2009, 106, 11454-11459.

(12) Ceppatelli, M.; Bini, R. Macromol. Rapid Commun. 2014, 35, 787-793.

(13) Evlyukhin, E.; Museur, L.; Traore, M.; Nikitin, S. M.; Zerr, A.; Kanaev, A. J. Phys. Chem. B 2015, 119, 3577-3582.

(14) Citroni, M.; Ceppatelli, M.; Bini, R.; Schettino, V. J. Phys. Chem. B 2007, 111, 3910-3917.

(15) Guan, J. W.; Song, Y. J. Chem. Phys. 2016, 144.

(16) Bernasconi, M.; Chiarotti, G. L.; Focher, P.; Parrinello, M.; Tosatti, E. Phys. Rev. Lett. 1997, 78, 2008-2011.

(17) Sakashita, M.; Yamawaki, H.; Aoki, K. J. Phys. Chem. 1996, 100, 9943-9947.

(18) Baonza, V. G.; Montoro, O. R.; Taravillo, M.; Caceres, M.; Nunez, J. J. Chem. Phys. 2004, 121, 11156-11162.

(19) Chiang, C. K.; Fincher Jr, C.; Park, Y. W.; Heeger, A. J.; Shirakawa, H.; Louis, E. J.; Gau, S. C.; MacDiarmid, A. G. Phys. Rev. Lett. 1977, 39, 1098.

(20) Coyle, J. D. Photochemistry of the $\mathrm{C} \equiv \mathrm{C}$ bond, in The Carbon-Carbon Triple Bond: Volume 2 (1978) (ed S. Patai), John Wiley \& Sons, Ltd., Chichester, UK.

(21) Dong, Z. H.; Song, Y. J. Phys. Chem. C 2010, 114, 1782-1788.

(22) Ibberson, R. M.; Prager, M. Acta Crystallogr. Sect. B 1995, 51, 71-76.

(23) McKean, D. C.; Mackenzie, M. W.; Morrisson, A. R.; Lavalley, J. C.; Janin, A.; Fawcett, V.; Edwards, H. G. M. Spectrochim. Acta Mol. Biomol. 1985, 41, 435-450.

(24) Thomsen, C. L.; Madsen, D.; Keiding, S. R.; Thogersen, J.; Christiansen, O. J. Chem. Phys. 1999, 110, 3453-3462.

(25) Elles, C. G.; Rivera, C. A.; Zhang, Y.; Pieniazek, P. A.; Bradforth, S. E. J. Chem. Phys. 2009, 130.

(26) Elles, C. G.; Shkrob, I. A.; Crowell, R. A.; Bradforth, S. E. J. Chem. Phys. 2007, 126.

(27) Nikogosyan, D. N.; Angelov, D. A. Chem. Phys. Lett. 1981, 77, 208-210.

(28) Nikogosyan, D. N.; Oraevsky, A. A.; Rupasov, V. I. Chem. Phys. 1983, 77, 131-143. 
(29) Andersson, S.; Al-Halabi, A.; Kroes, G. J.; van Dishoeck, E. F. J. Chem. Phys. 2006, 124.

(30) Harris, S. J.; Murdock, D.; Zhang, Y. Y.; Oliver, T. A. A.; Grubb, M. P.; Orr-Ewing, A. J.; Greetham, G. M.; Clark, I. P.; Towrie, M.; Bradforth, S. E.; Ashfold, M. N. R. Phys. Chem. Chem. Phys. 2013, 15, 6567-6582.

(31) Durig, J. R.; Feng, F. S.; Wang, A. Y.; Phan, H. V. Can. J. Chem. 1991, 69, 1827-1844.

(32) Ceppatelli, M.; Bini, R.; Schettino, V. J. Phys. Chem. B 2009, 113, 14640-14647.

(33) Ceppatelli, M.; Bini, R.; Caporali, M.; Peruzzini, M. Angew. Chem. Int. Ed. 2013, 52, 2313-2317.

(34) Ceppatelli, M.; Bini, R.; Schettino, V. Phys. Chem. Chem. Phys. 2011, 13, 1264-1275.

(35) Reusch, W. "Virtual textbook of organic chemistry", 1999.

(36) Wagner, W.; Saul, A.; Pruss, A. J. Phys. Chem. Ref. Data 1994, 23, 515-527.

(37) Collins, S. J. Phys. Chem. 1990, 94, 5240-5243.

(38) Lee, H. Y.; Kislov, V. V.; Lin, S. H.; Mebel, A. M.; Neumark, D. M. Chem. Eur. J. 2003, 9, 726-

740.

(39) Palmer, M. H.; Walker, I. C. Chem. Phys. 2007, 340, 158-170.

(40) Deschênes, J.; Deslauriers, H.; Collin, G. J. Can. J. Chem. 1980, 58, 2108-2114.

(41) Fahr, A.; Laufer, A. H. J. Phys. Chem. A 2005, 109, 2534-2539.

(42) Guan, J. W.; Song, Y. J. Phys. Chem. B 2015, 119, 3535-3545.

(43) Hoell, D.; Mensing, T.; Roggenbuck, R.; Sakuth, M.; Sperlich, E.; Urban, T.; Neier, W.; Strehlke, G. Ullmann's Encyclopedia of Industrial Chemistry 2009. 


\section{Figure captions}

Figure 1. (a) Selected IR spectra of 2-butyne mixed with small amount of water collected at room temperature with different initial loading pressures. (b) Pressure dependence of selected IR active modes of 2-butyne. Three pressure regions with different colors indicate different phases (see text). The inset shows the crystal structure of 2-butyne in phase II.

Figure 2. IR spectra of 2-butyne and $\mathrm{H}_{2} \mathrm{O}$ at pressure 0.27 (a), 0.52 (b) and $0.90 \mathrm{GPa}$ (c) upon UV irradiation (with $\lambda$ of $\sim 350 \mathrm{~nm}$ and power of $\sim 250 \mathrm{~mW}$ ) as a function of time in the spectral region of $670-1310 \mathrm{~cm}^{-1}$.

Figure 3. IR spectra of 2-butyne and $\mathrm{H}_{2} \mathrm{O}$ at pressure 0.27 (a), 0.52 (b) and $0.90 \mathrm{GPa}$ (c) upon UV irradiation (with $\lambda$ of $\sim 350 \mathrm{~nm}$ and power of $\sim 250 \mathrm{~mW}$ ) as a function of time in the spectral region of 1600-1800 $\mathrm{cm}^{-1}$. The insets show corresponding microphotographs (60 microns in diameter) of 2-butyne $/ \mathrm{H}_{2} \mathrm{O}$ mixture collected before and after irradiation.

Figure 4. Schematics showing three possible processes following a photodissociation event that produces a pair of $\mathrm{H}$ and $\mathrm{OH}$ radicals within a water cage. The $\mathrm{H}$ and $\mathrm{OH}$ radical pair can escape the solvent cage and persist separately in solution or diffusively recombine to form original $\mathrm{H}_{2} \mathrm{O}$ molecule. The $\mathrm{H}$ and $\mathrm{OH}$ radical pair could also remain within the original $\mathrm{H}_{2} \mathrm{O}$ cage and recombine on a much faster timescale than that for diffusive recombination (see Ref. 30). The escaped $\mathrm{H}$ atoms are proposed to react with 2-butyne and give rise to 2-butene.

Figure 5. Relative photochemical reaction yields of (a) 2-butene and (b) 2-butanone estimated by integrating the IR absorbance of the respective characteristic IR modes as a function of radiation time for 2-butyne-water mixture with an initial loading pressure of $0.04,0.27,0.52$ and $0.90 \mathrm{GPa}$. 
Table 1. Assignment and Frequencies of Observed Raman and Infrared Modes in Comparison with References.

\begin{tabular}{cccc}
\hline \multirow{2}{*}{ Mode } & Experimental & References $^{\text {a }}$ & \\
\cline { 2 - 3 } & IR (in cm Description $\left.^{-1}\right)$ & Raman & \\
\hline$v_{13}$ & 2961 & 2963 & $\mathrm{CH}_{3}$ stretching \\
$v_{1}$ & 2916 & 2921 & $\mathrm{C}-\mathrm{H}$ stretching \\
$2 v_{14}$ & 2862 & 2863 & $\mathrm{CH}_{3}$ deformation \\
$2 v_{3}$ & 2744 & 2738 & $\mathrm{CH}_{3}$ deformation \\
$2 v_{8}$ & 2330 & 2315 & $\mathrm{C}-\mathrm{C}$ stretching \\
$v_{2}$ & & 2238 & $\mathrm{C} \equiv \mathrm{C}$ stretching \\
$v_{14}$ & 1448 & 1448 & $\mathrm{CH}_{3}$ deformation \\
$v_{3}$ & & 1379 & $\mathrm{CH}_{3}$ deformation \\
$v_{11}$ & 1035 & & $\mathrm{CH}_{3}$ rocking \\
\hline
\end{tabular}

a) Ref. 18 
Table 2. The Observed IR Bands of 2-butyne and Water with an Initial Loading Pressure of 0.27, 0.52, 0.90 GPa and Those of Photochemical Reaction Products after UV Irradiation $(\lambda=350 \mathrm{~nm}, 250 \mathrm{~mW})$.

\begin{tabular}{|c|c|c|c|c|c|c|c|c|}
\hline \multicolumn{6}{|c|}{ This work } & \multicolumn{3}{|c|}{ References } \\
\hline \multicolumn{4}{|c|}{$0.27 \mathrm{GPa}$} & \multirow{2}{*}{$\begin{array}{l}0.52 \mathrm{GPa} \\
100 \mathrm{~min}\end{array}$} & \multirow{2}{*}{$\begin{array}{l}0.90 \mathrm{GPa} \\
135 \mathrm{~min}\end{array}$} & \multicolumn{2}{|c|}{ 2-butene (solid) ${ }^{\mathrm{a}}$} & \multirow{2}{*}{$\begin{array}{c}\text { 2-butanone } \\
\text { solid }\end{array}$} \\
\hline $0 \min$ & $30 \mathrm{~min}$ & $45 \mathrm{~min}$ & $100 \mathrm{~min}$ & & & cis & trans & \\
\hline & 676 & 676 & 676 & 676 & & $682 \mathrm{vs}$ & & \\
\hline & & 752 & 752 & 752 & 746 & & & $745 \mathrm{~m}$ \\
\hline & & 770 & 770 & 770 & 768 & & & $768 \mathrm{~s}$ \\
\hline & & 883 & 886 & 887 & & $868 \mathrm{vw}$ & & \\
\hline & & 910 & & 910 & & & & $937 \mathrm{~s}$ \\
\hline & 966 & 969 & 969 & 968 & & $972 \mathrm{~s}$ & $974 \mathrm{vs}$ & \\
\hline & 976 & & & 978 & 973 & & 983vs & $995 \mathrm{~s}$ \\
\hline \multirow[t]{3}{*}{1040} & 1041 & 1038 & 1037 & 1036 & 1039 & $1038 \mathrm{~m}$ & $1043 \mathrm{~s}$ & \\
\hline & & 1065 & 1065 & 1067 & & & $1061 \mathrm{~s}$ & \\
\hline & & 1093 & & 1090 & 1090 & & & $1087 \mathrm{~s}$ \\
\hline \multirow[t]{4}{*}{1145} & 1145 & 1145 & 1150 & 1150 & 1146 & & & \\
\hline & & 1303 & 1302 & 1302 & & & $1303 w$ & \\
\hline & 1660 & 1660 & 1661 & 1661 & 1661 & $1661 \mathrm{~m}$ & & $1668 \mathrm{~m}$ \\
\hline & & 1724 & 1722 & 1717 & 1719 & $1722 \mathrm{w}$ & & $1716 \mathrm{vs}$ \\
\hline 2855 & 2856 & 2859 & 2862 & 2870 & 2865 & $2860 \mathrm{~m}$ & $2860 \mathrm{~m}$ & \\
\hline 2923 & $2923 \mathrm{~s}$ & $2923 \mathrm{~s}$ & 2923 & 2925 & 2925 & $2922 \mathrm{~s}$ & $2918 \mathrm{~m}$ & $2920 \mathrm{~m}$ \\
\hline \multirow[t]{2}{*}{2965} & 2964 & $2964 \mathrm{~s}$ & 2963 & 2962 & 2965 & $2965 \mathrm{~s}$ & $2966 \mathrm{~s}$ & \\
\hline & 3020 & $3023 \mathrm{~s}$ & 3023 & $3025 \mathrm{w}$ & & $3014 \mathrm{~s}$ & $3014 \mathrm{~s}$ & \\
\hline
\end{tabular}

a) Ref. 23

b) Ref. 31 
(a)

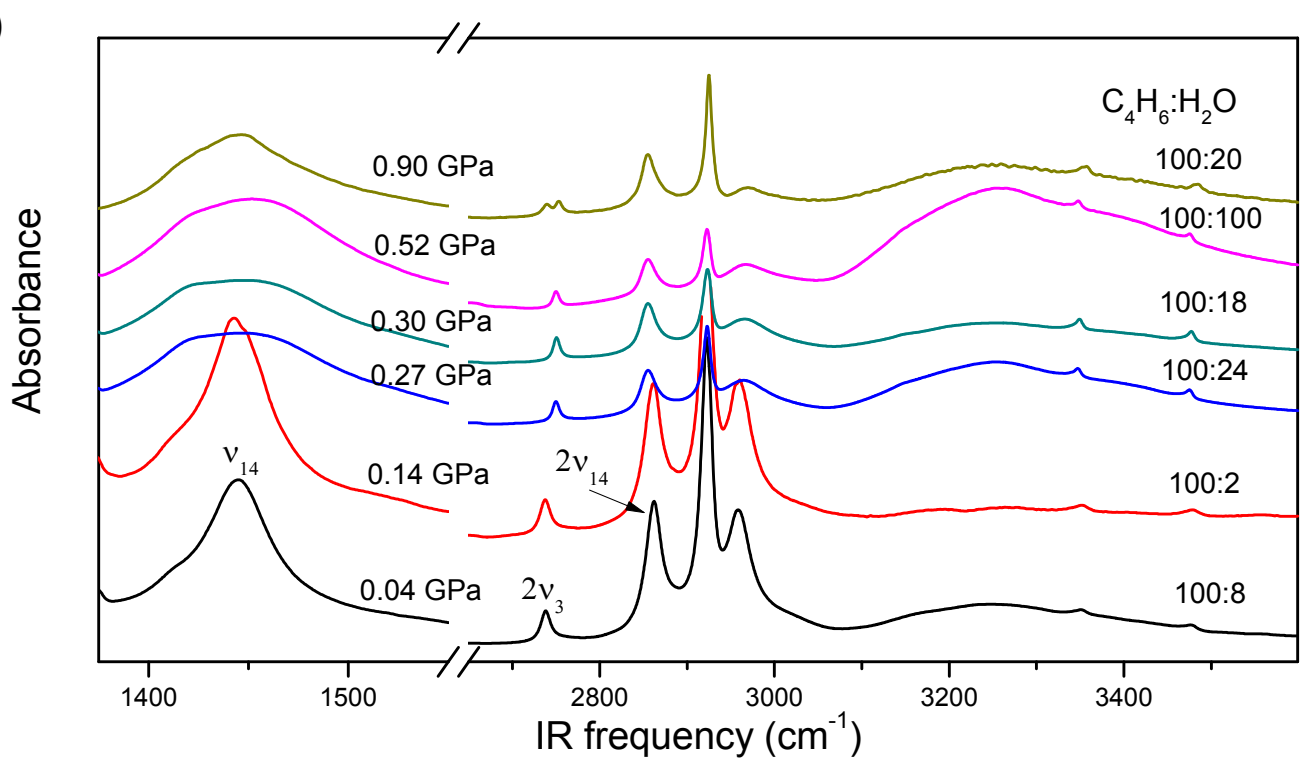

(b)

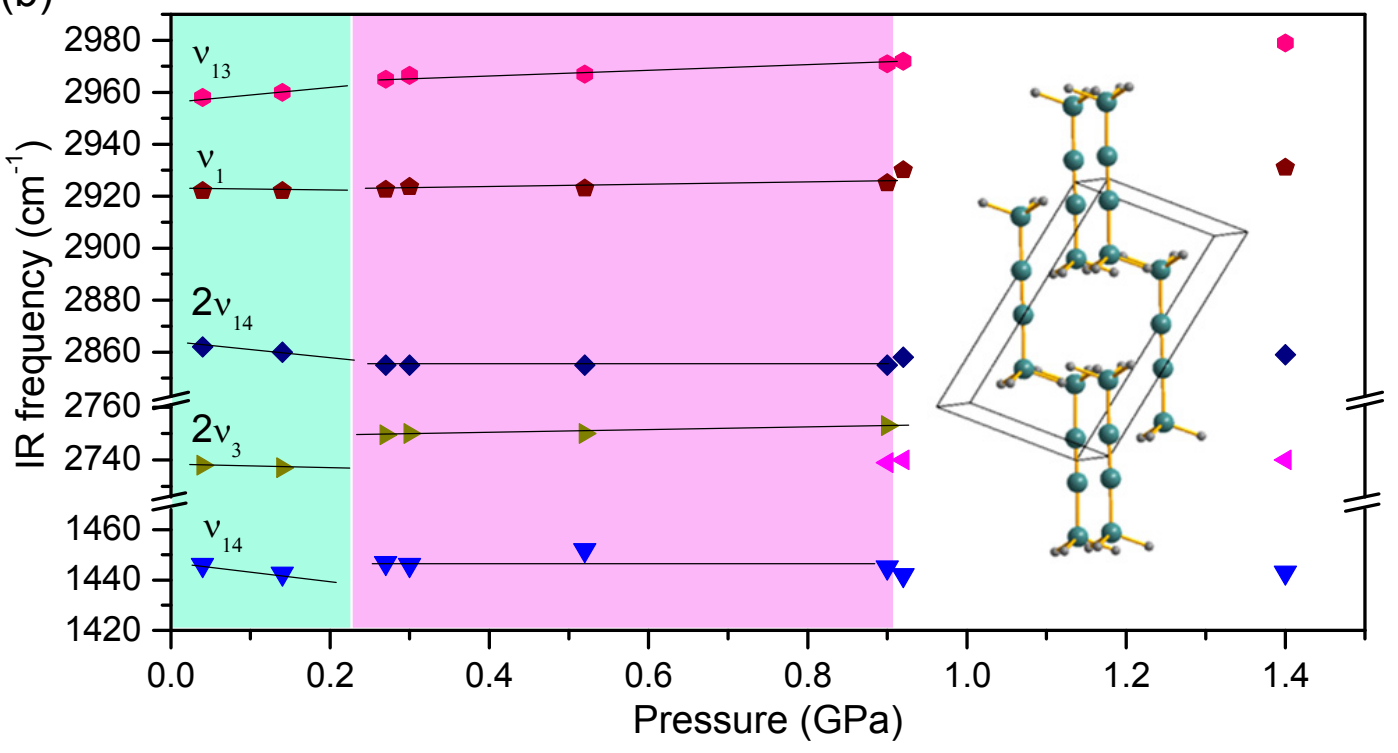




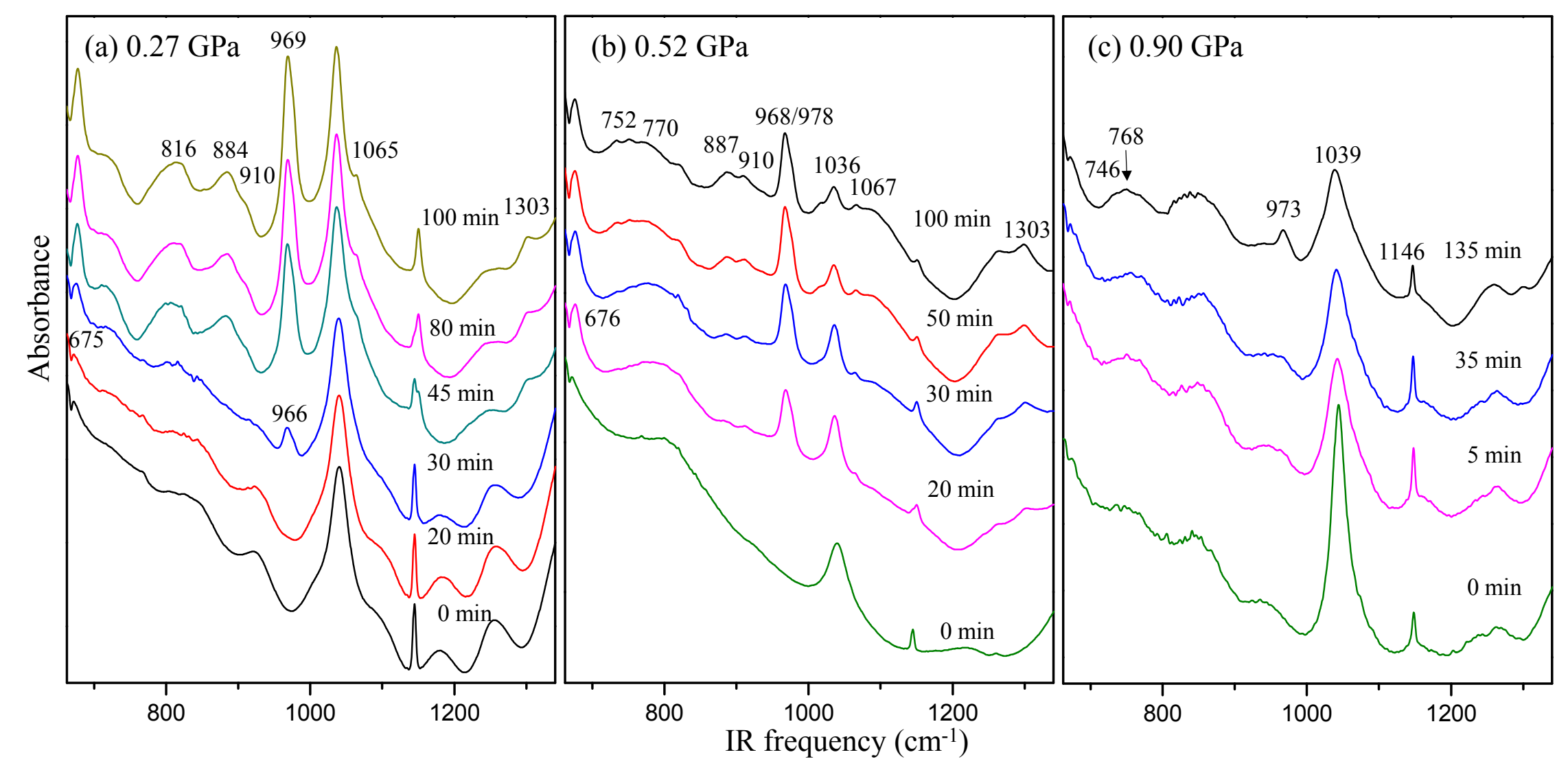



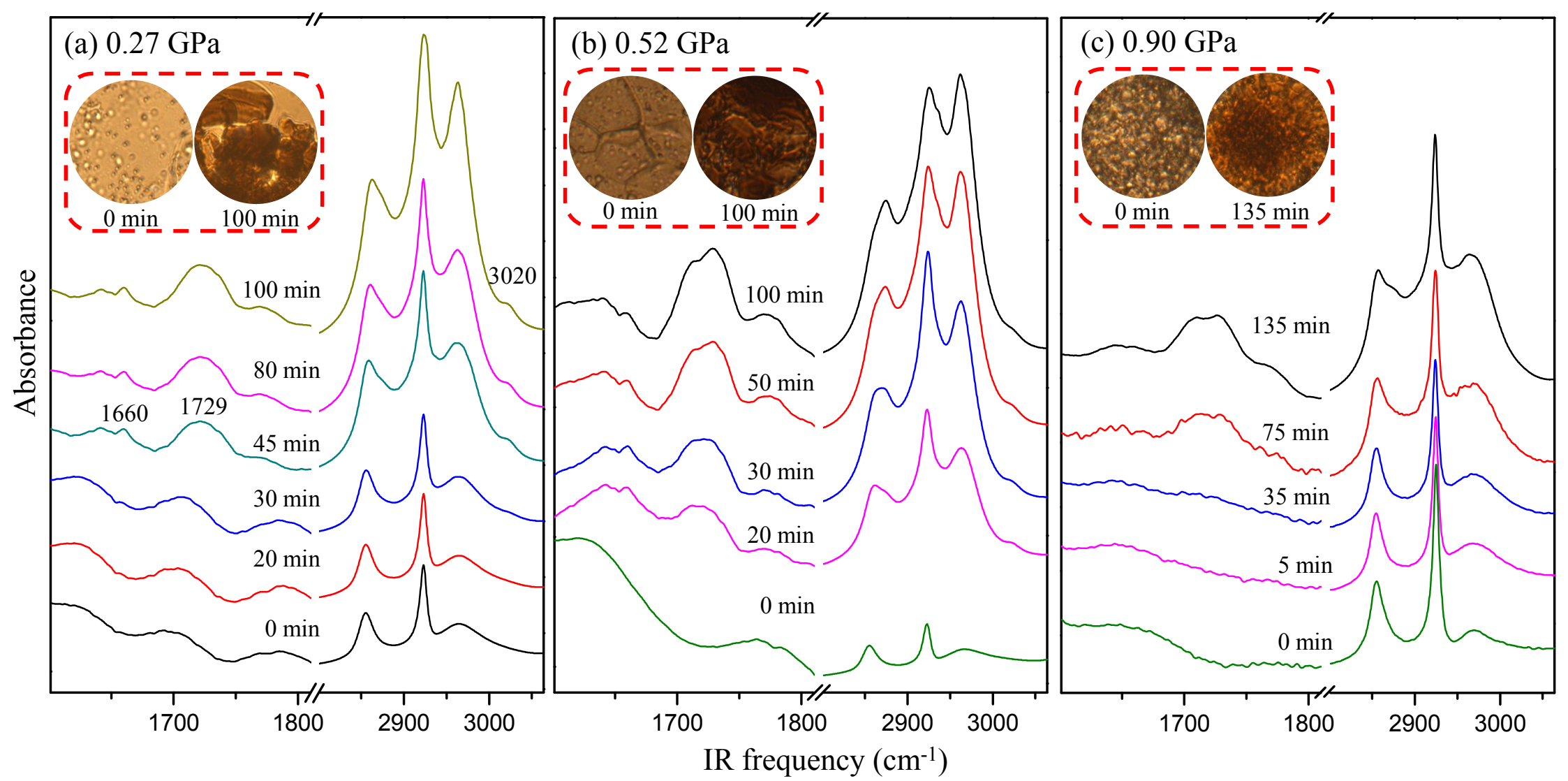


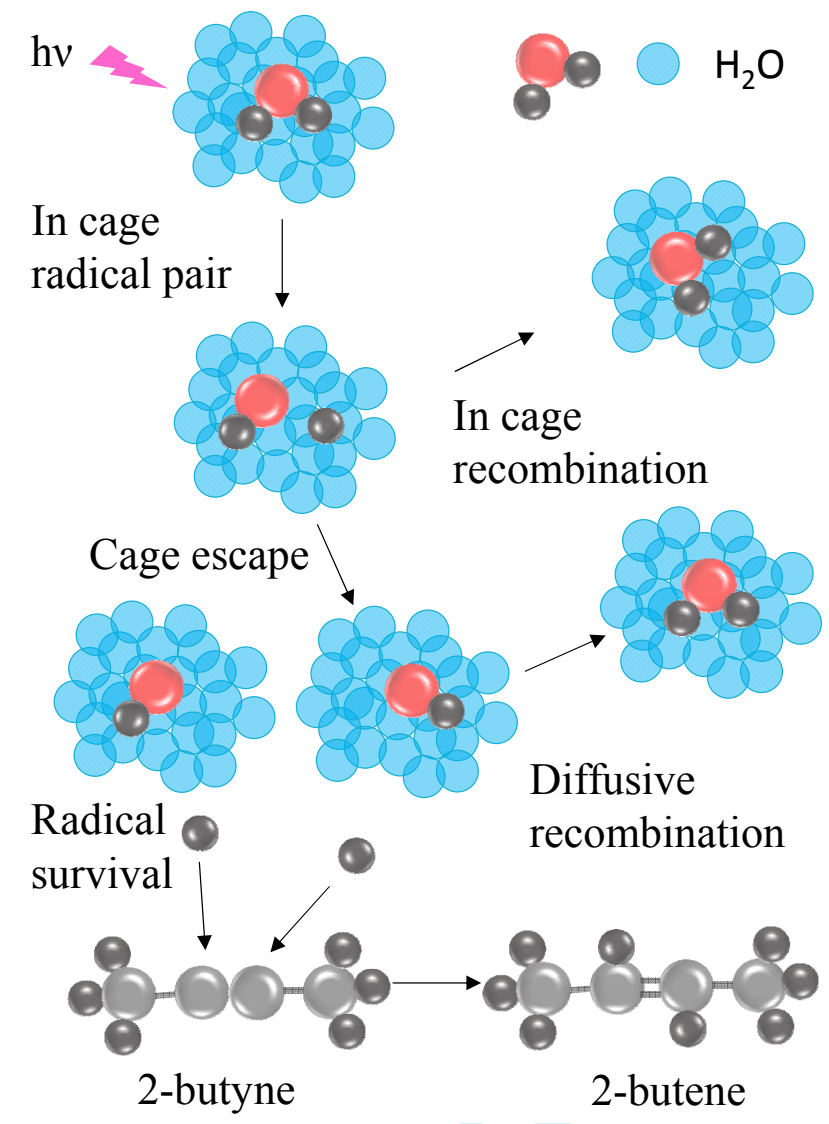

https://mc06.manuscriptcentral.com/cjc-pubs 

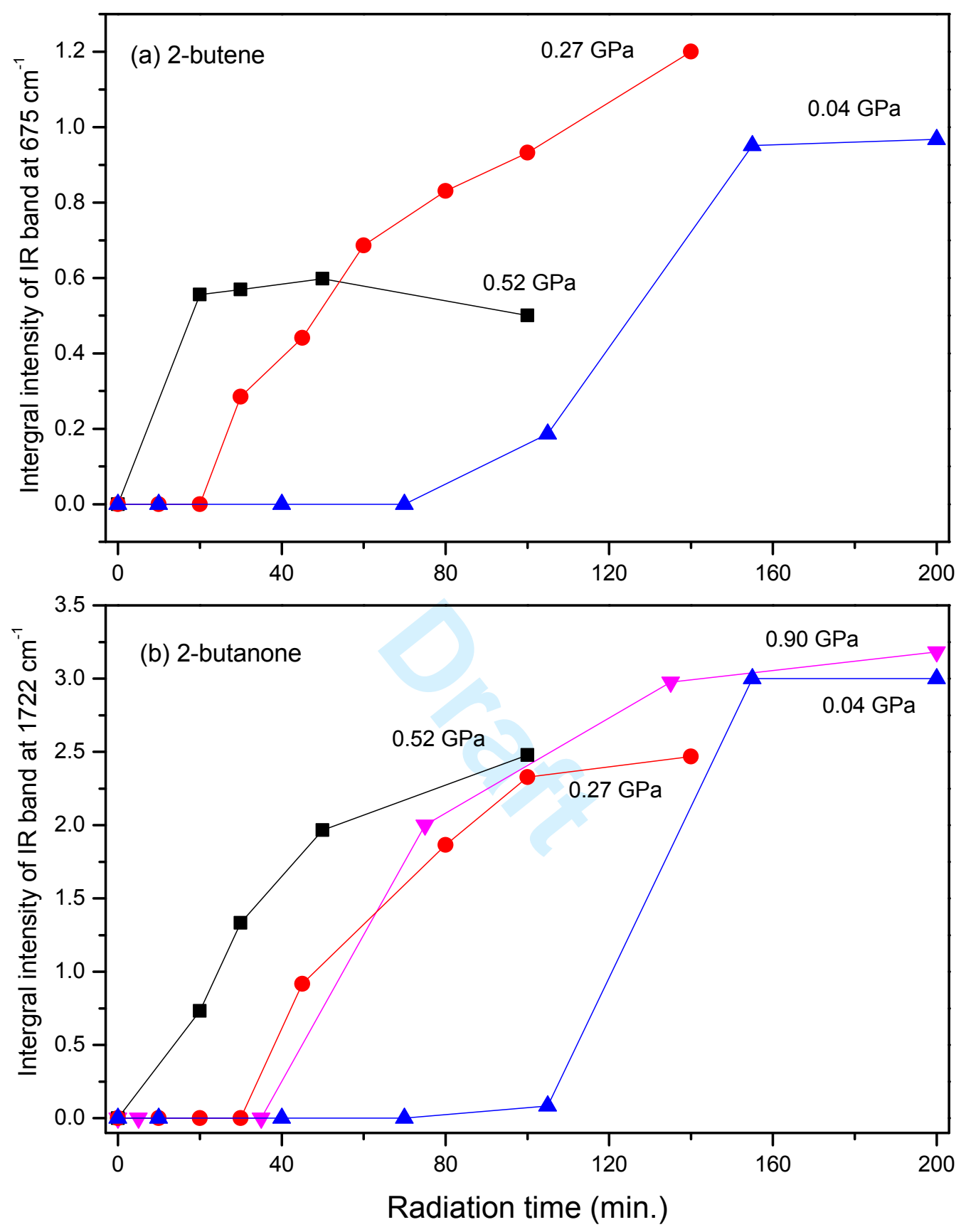